\title{
CFD Simulation Study on Mixing Experiment of Anaerobic Digestion Tank
}

\author{
Zhu Hongguang*, JingRui \\ School of Mechanical Engineering and Energy, Tongji University, Shanghai 201804,China
}

\begin{abstract}
The anaerobic fermentation produces biogas with the participation of sensitive microorganisms. The smooth fermentation needs to ensure good heat transfer and mass transfer effects. Stirring is very important to create these fermentation conditions. In this paper, the computational fluid dynamics method is used to simulate the flow field inside a fully-mixed stirred anaerobic reactor. It is divided into a single-layer six-leaf open-type turbine with baffles and two-layer four-leaf inclined 45-degree paddles. Group conditions, and quantitative calculation and analysis of the internal flow field of the simulated reactor. The effects of different blades and different stirring speeds are investigated. The results show that the double-layer oblique upward paddle can produce a better axial velocity distribution, which is more conducive to the formation of a large fluid loop structure that circulates up and down. The average speed of double-layer agitation at 125 $320 \mathrm{rpm}$ is less than the average speed of a single layer, but the speed of double-layer agitation at $60 \mathrm{rpm}$ is greater than the speed of a single layer.
\end{abstract}

\section{Introduction}

Biogas, as a clean and renewable energy, is attracting more and more attention from all walks of life in China[1]. It provides clean energy and also solves the problem of organic waste pollution [2-3]. However, due to the limitation of management level and technical conditions, many biogas projects are not in normal operation. The most prominent problems are two kinds: first, the heat transfer in the biogas digester, that is, the temperature environment in the digester is not ideal, and there is no gas production in winter. In order to solve this problem, some researchers have used solar energy and ground source heat pump to heat [4-5] in recent years, and achieved preliminary results. But this has not solved all the problems. Because of the lack of stirring scheme, the temperature field in biogas digester is uneven [6]. As a result, a good fermentation environment has not been created, and the gas production effect of these biogas projects is still not good. In addition, along with the bad heat transfer effect, there is also a kind of mass transfer problem, which is mainly due to the unreasonable mixing, resulting in the uneven concentration field in the biogas digester. Specifically, there are stirring dead zone, scum crust near the liquid level, bottom sediment accumulation in the biogas digester, etc. [7], which will eventually lead to the failure of fermentation. The essence of stirring [8] is to indirectly affect the fermentation efficiency by influencing the temperature field in the fermentation tank, the effect of mass transfer between fermentation substrate and microorganisms, and the release of gas. Stirring in anaerobic digestion can transport the substrate needed for microbial growth, uniform the $\mathrm{pH}$ and temperature fields in the fermentation reactor, dilute inhibitors, prevent sediment and short flow [9-10]. In industrial production, mixing devices are often used to mix fluids..

At present, the design of many mixing equipment also depends on the experience and intuitive judgment of engineers. As a result of these empirical judgments, some errors often occur [11]. With the development and wide application of CFD numerical simulation technology, transfer computational fluid dynamics (CFD) technology has been used as an effective tool for reaction analysis, monitoring and optimizing digestion containers[12]. CFD is based on the numerical solution of the equations expressing mass, momentum and energy[13]. Finally, these equations are combined with the transport equation of the fluid under certain operating conditions to describe the mass or heat transfer process of the fluid [14]. Researchers have done a lot of research on the reactor of hydrogen and methane production, including heat transfer, mass transfer, mixing, etc. [15-16].

The flow field in the test facility was quantitatively simulated by CFD technology. The baffle reactor equipped with a six-blade turbine agitator and two baffle reactor equipped with a 45 degree inclined blade slurry were used to extract the data of the fluid state in the reactor. To realize the predictability and controllability of anaerobic digestion tank stirring design, lay the foundation for further development of anaerobic digestion tank stirring computer-aided design system, and create the necessary theoretical basis for the formulation of relevant standards and technical specifications in the future.

\section{Subjects and methods}

\footnotetext{
* Zhu Hongguang: zhuhg@tongji.edu.cn
} 


\subsection{Research object}

The research object is a self-made organic glass biogas reactor.

The inner dimension of the double-layer inclined stirred reactor is $\mathrm{T}=0.3 \mathrm{~m}$ in diameter and $\mathrm{H}=0.3 \mathrm{~m}$ in height. The designed volume of the reactor is $\mathrm{V}=0.020 \mathrm{~m} 3$. The mixing device is mechanically sealed. The agitator is 45 degree inclined blade pulp. In order to keep warm, an insulating belt is added to the outer wall, and a feeding, pressure regulating and air outlet device is left at the top. The agitation system is centrally stirred. The diameter of the blade is $\mathrm{D}=0.1 \mathrm{~m}$, the thickness of the blade is delta $=$ $0.002 \mathrm{~m}$, the height $\mathrm{C}$ from the bottom is 0.07 and $0.22 \mathrm{~m}$, and the width of the baffle is $0.03 \mathrm{~m}$.
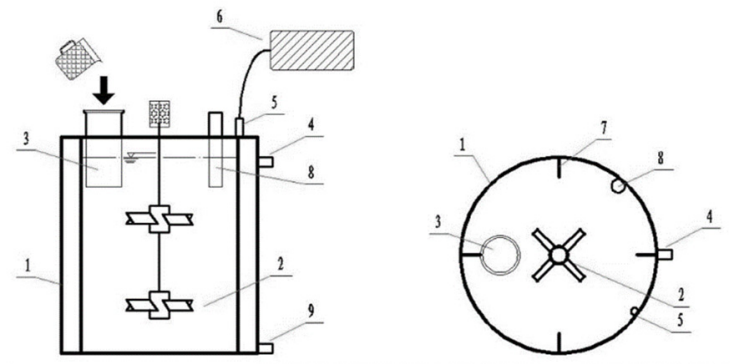

1. Reactor 2. Stirrer 3. Feed pipe 4. Outlet pipe 5. Outlet hole 6. Bag 7. Baffle 8. Pressure regulator 9. Sludge discharge port

Fig. 1. Schematic diagram of double-layer reactor system

The inner dimension of single-layer Rushton stirred reactor is $\mathrm{T}=0.3 \mathrm{~m}$ in diameter, $\mathrm{H}=0.3 \mathrm{~m}$ in height, and the designed volume of reactor is $\mathrm{V}=0.020 \mathrm{~m} 3$. The mixing device is mechanically sealed. The agitator is 45 degree inclined blade pulp. In order to keep warm, an insulating belt is added to the outer wall, and a feeding, pressure regulating and air outlet device is left at the top. The stirring system is centrally stirred. The diameter of blade is $\mathrm{d}=0.1 \mathrm{~m}$, the thickness of blade is delta $=0.002 \mathrm{~m}$, the height $\mathrm{C}$ from bottom is $0.10 \mathrm{~m}$, and the width of baffle is $0.03 \mathrm{~m}$.
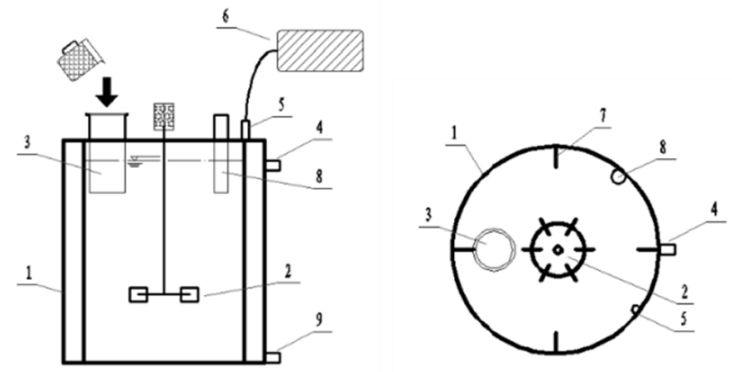

1. Reactor 2. Stirrer 3. Feed pipe 4. Outlet pipe 5. Outlet hole 6. Bag 7. Baffle 8. Pressure regulator 9. Sludge discharge port

Fig. 2. Schematic diagram of single-layer reactor system

\subsection{Simulation method}

The commercial computational fluid dynamics software FLUENT is used in the simulation calculation. The software uses the finite volume method to discretize the control differential equation [17]. The simulation process includes establishing a computer mesh model, determining the boundary conditions and initial conditions, and solving the mass, momentum and energy equations. The designed rotational speeds of the two reactors are $n=60,125,190,255$ and $320 \mathrm{rpm}$.

\subsubsection{Computational model}

The turbulence model is simulated by the standard k- $\varepsilon$ model, which has been successfully applied to the analysis of similar problems [18]. At present, the main simulation methods widely used in blade rotation are multi-reference frame method (MRF) and sliding grid method (SG)[19]. Under the same calculation conditions, the results of the two methods are basically the same, but the amount of MRF calculation is one order of magnitude smaller, and the SG method requires a high level of hardware equipment [20-21]. In this paper, the multiple reference frame method (MRF) is used to simulate the blade and the fluid region near the blade in rotating coordinate system, and the rest in stationary coordinate system.

$$
\frac{\partial(\rho u)}{\partial x}+\frac{\partial(\rho v)}{\partial y}+\frac{\partial(\rho w)}{\partial z}=0
$$

In the equation, $\rho$ is density, $\mathrm{u}, v$ and $w$ are components of velocity vectors in $\mathrm{x}, \mathrm{y}$ and $\mathrm{z}$ directions.

Momentum equation, energy equation and twoequation model describing turbulence can be expressed by general governing equation.

$$
\frac{\partial(\rho \phi)}{\partial t}+\operatorname{div}(\rho u \phi)=\operatorname{div}(\operatorname{Tgrad} \phi)+S
$$

In the equation, $\phi$ is a general variable, and can represent $u, v, w$, temperature $\mathrm{T}$, turbulent energy $\mathrm{k}$ and turbulent dissipation rate $\varepsilon$ in different equations; $\Gamma$ is a diffusion coefficient; $\mathrm{S}$ is a source term.

The pressure and velocity equations are coupled in SIMPLE mode and discretized in upwind mode. The simulation type is steady simulation[22].

\subsubsection{Mesh generation and boundary conditions}

The simulated shape is the same as the actual shape of the reactor, which is filled with liquid. Water is used instead of water in liquid simulation.

GAMBIT (FLUENT pre-processing software) is used to divide grids, and unstructured tetrahedral grids are used in the model. An important problem in mesh generation is to make the simulation results not correlated with any mesh [23]. In computational simulation, a circular region is divided near the impeller to distinguish the other parts. The number of grids is sufficient to describe the flow details.

\section{Results}

\subsection{Simulation results of double-layer agitation}


It can be seen from the simulated velocity distribution of each layer in figs. 3 and 4 that the flow is concentrated in the direction of mixer and its mixing pusher, and the flow velocity is small in other positions. When the water flow from the mixer meets the bottom reactor wall, the direction of the water flow changes rapidly and diffuses into the flow field. The upper part of the reactor stirred little, while the lower part of the reactor flowed violently. In this case, the main flow cycle is concentrated in the lower half of the reactor. In addition, the impeller impels the flow to diffuse into the wall backward flow field, centering on the vertical section where the impeller is located, and the flow presents a certain degree of left-right symmetry in the horizontal direction.

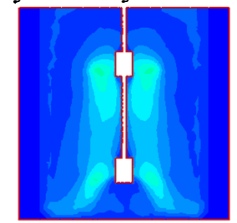

a

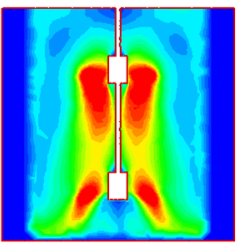

d

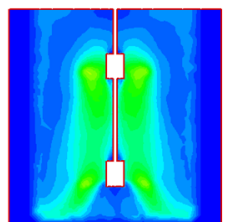

b
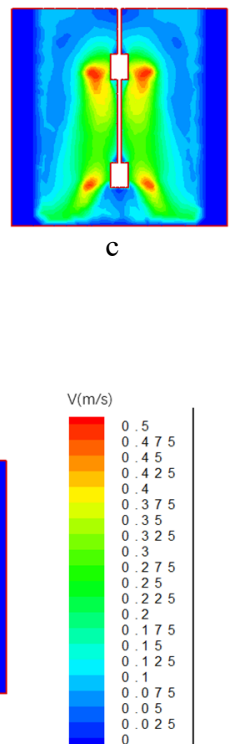

a-e corresponds to $\mathrm{n}=60,125,190,225$ and 320 RPM doublelayer stirred reactors, respectively

Fig. 3. Velocity equivalent map of vertical section of doublelayer mixing
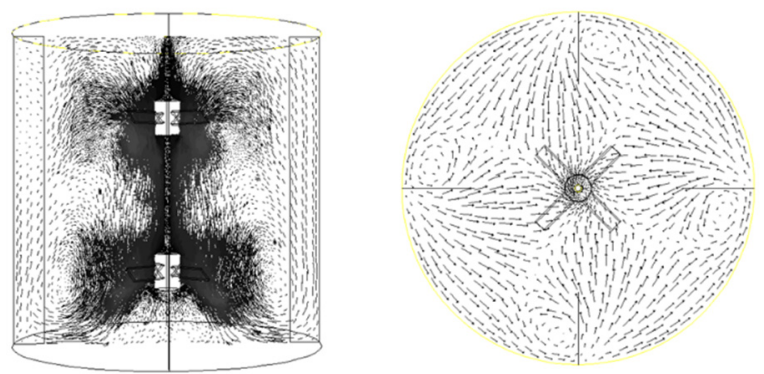

Fig. 4. Velocity vector map of $60 \mathrm{rpm}$ double-layer mixing

The velocity vector diagram of the simulated axial section is shown below. From the figure, we can see the axial large circulation flow pattern and the small fluid ring near the lower impeller. The fluid from the tip of the agitator moves obliquely towards the stirring vessel wall. The downward axial part meets the bottom of the vessel and changes the flow direction. It flows upward along the surrounding wall to form a large fluid ring, which is divided into two parts. One reaches near the liquid surface and the other part is driven by the lower agitator to the lower agitator so as to form a downward flow. Part fluid ring. The upward part returns to the stirring shaft from the liquid level and flows back to the blade to form a large circulation flow pattern. At the same time, a radial fluid ring is formed at the position of two impellers, and the range of the radial fluid ring is relatively small due to the existence of the surrounding baffles (Fig. 5).
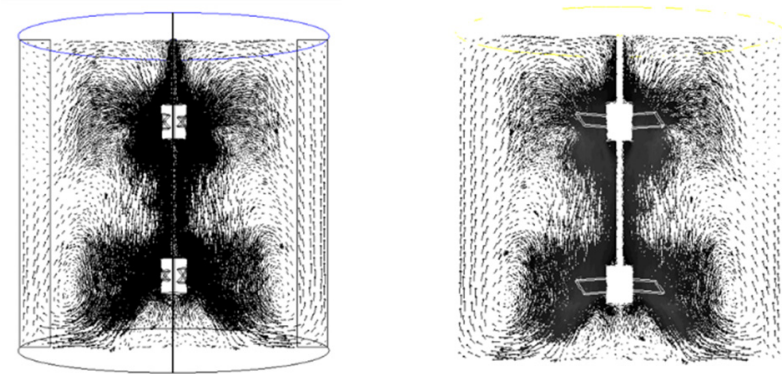

Fig. 5. Velocity vector map of $320 \mathrm{rpm}$ double-layer mixing

Figure 4 shows the velocity vector when the speed is $60 \mathrm{rpm}$. Compared with the speed of $320 \mathrm{rpm}$ (Figure 5), it can be seen that the change of the speed of the agitator has no effect on the flow field shape inside the kettle. The number, position and shape of the fluid rings on the axial section have not changed greatly, but the absolute velocity of the fluid has increased gradually. The simulation results are consistent with the results reported in many literatures that the shape of the flow field is not affected by Reynolds number in a certain range [24].

The velocity components on the axis line of stirred tank and the horizontal center line parallel to the liquid level are discussed below. Fig. $6 \mathrm{C}$ is the distribution of the combined velocity and velocity components on the axis line of $60 \mathrm{rpm}$ tank. It is stipulated that the radial velocity is positive and negative from the center of the groove to the groove wall; the axial velocity is positive and negative from the direction of gravity acceleration; the tangential velocity is positive and negative from the downward direction of the liquid. Fig. $6 \mathrm{~B}$ is an axial velocity distribution image of 190rpm and Fig. 6A is an axial velocity distribution image of $320 \mathrm{rpm}$. It can be seen from the graph that the flow field shape does not change with the increase of stirring speed in a certain range, but the absolute velocity of the flow increases. It can be seen from the graph that the combined velocity and the distribution of each velocity component on the axis line of the groove. The main speed on the axis of the tank increases with the increase of agitation speed. The axial velocity value of the reactor center axis is upward near the reactor side wall, while downward flow occurs at the reactor center position driven by the agitator impeller. This flow trend can form the flow state of the upper and lower circulation. With the vertical section of the impeller as the center, the flow shows a certain degree of left-right symmetry in the horizontal direction, and the left-right flow pattern is the same.

Axial velocity changes from the upward direction of the tank wall to the downward direction as it approaches the stirring center, reaching its maximum at about 0.025 $\mathrm{m}$ away from the center, and the velocity distribution is symmetrical left and right. The tangential velocity keeps a negative direction, which indicates that the horizontal rotation direction of the flow field is the same as that of 
the impeller. However, the radial velocity of the flow field is smaller, which indicates that the exchange capacity between the upper and lower circulation layers is smaller at the position between the two impellers.

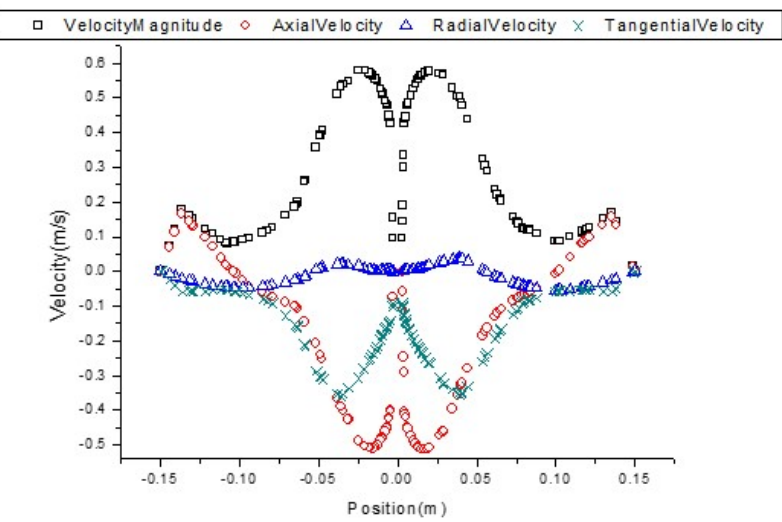

A

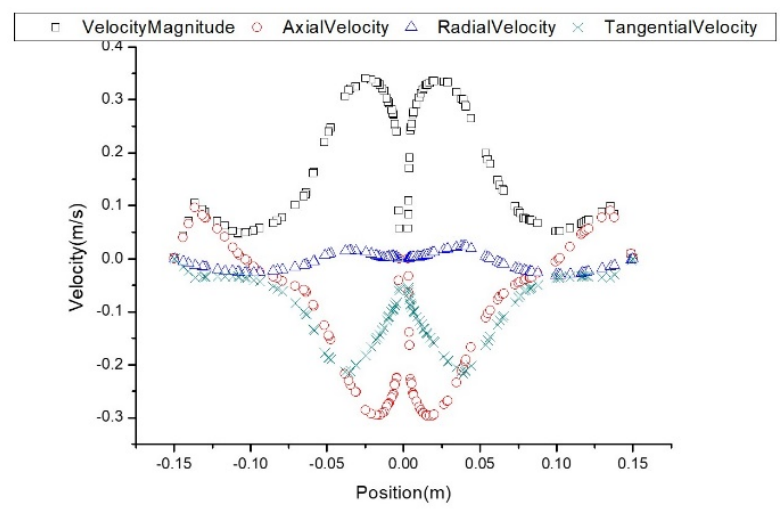

B

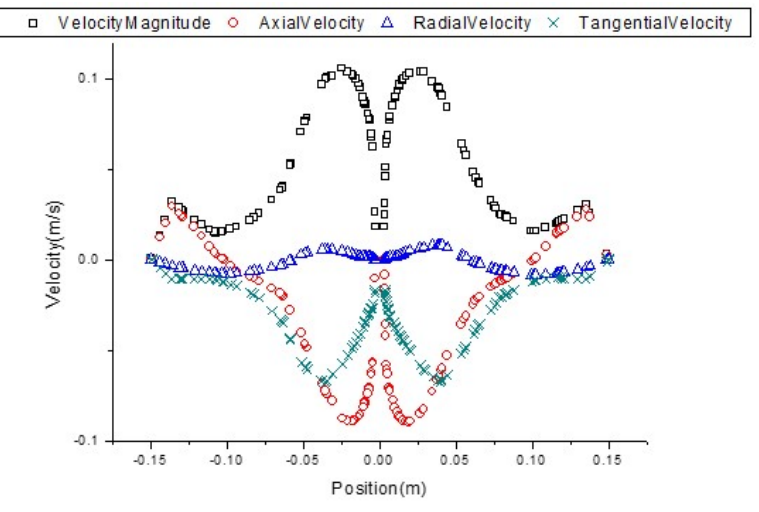

C

Fig. 6. Axial velocity distribution map of double-layer stirred reactor

\subsection{Simulation results of single-layer agitation}
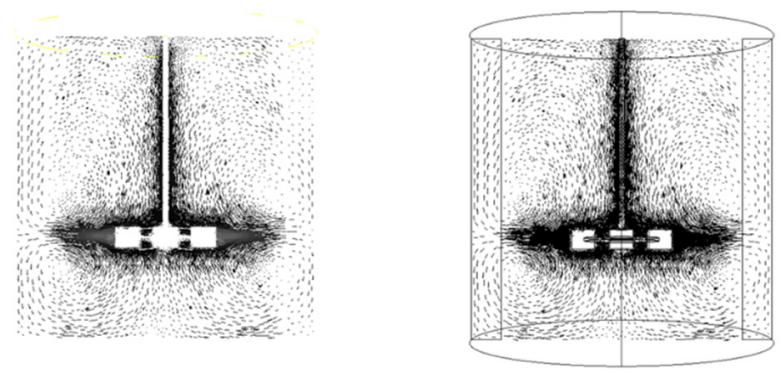

Fig. 7. Axial velocity distribution map of double-layer stirred reactor

Simulation results of $60 \mathrm{rpm}$ and $320 \mathrm{rpm}$ reactors for a and b, respectively

From figs. 7 , we can see that the change of impeller speed does not affect the flow field shape in the reactor. The number, position and shape of the fluid rings on the axial section have not changed greatly, but the absolute velocity of the fluid increases gradually.

From the analysis of the vector diagram, there are two loops on each side of the vertical section. The fluid is thrown out of the central region along the transverse direction of the impeller. When it meets the reactor wall, two streams of fluid flow along the upper and lower directions respectively. The upper fluid returns to the propeller region from the center of the liquid surface to form the upper fluid loop. The lower fluid continues to flow downward and moves backward when it touches the bottom of the reactor, and then is sucked into the central area of the propeller to form the lower fluid loop. The structure of the fluid loop is consistent with the literature.

The measuring points are arranged along $0.075,0.09$, $0.105,0.12$ and $0.135 \mathrm{~m}$ at the central side of the mixing shaft. Figure 8 shows the axial velocity distribution from top to bottom. Obviously, the change of impeller speed does not affect the shape of flow field inside the kettle, but the speed changes. Therefore, the linear velocity distribution of only three rotating speeds is given. It is found from the figure that there are two peaks of the axial velocity, which are located near 0.05 and 0.15 respectively and in the opposite direction. It shows that the upper and lower layers of flow are centered on the blade position, forming two fluid rings. Moreover, the lower velocity varies sharply, which indicates that the turbulence in this area is strong.

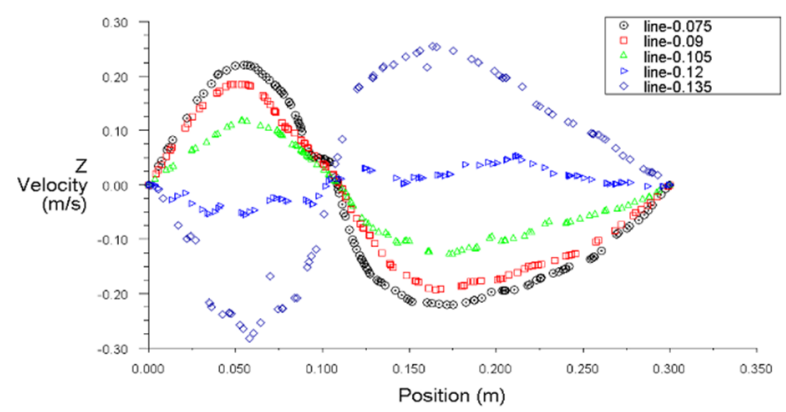




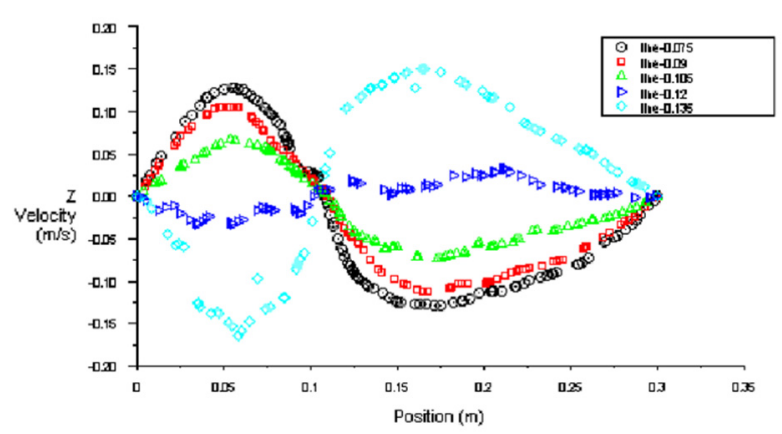

B

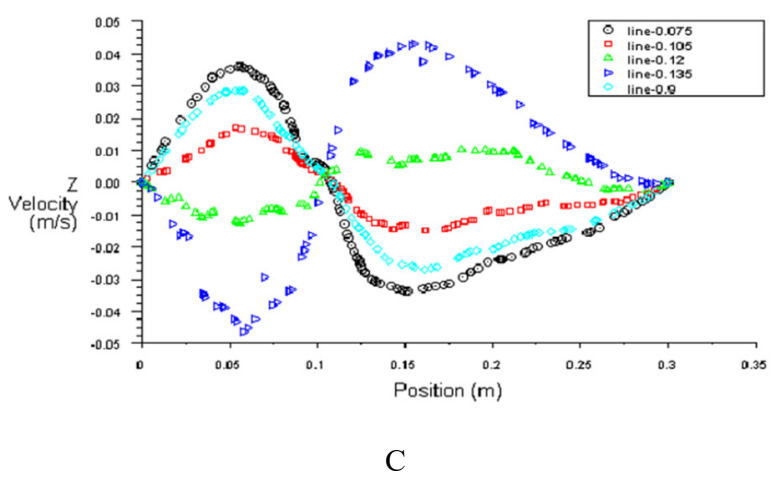

A, B and C correspond to 320, 190 and 60 rpm reactors respectively.

Fig. 8. The vertical axis velocity distribution of single-layer agitation

\section{Discussion}

Figure 9 shows the probability distribution of velocity, AE corresponds to $60,125,190,225$ and $320 \mathrm{rpm}$, respectively. It is found that with the increase of rotational speed, the maximum rotational speed increases rapidly, and the probability distribution image moves to the right of the coordinate axis in the same shape. The flow field velocity of the reactor is more concentrated below $0.5 \mathrm{~m} / \mathrm{s}$, and the distribution of the higher speed is less.

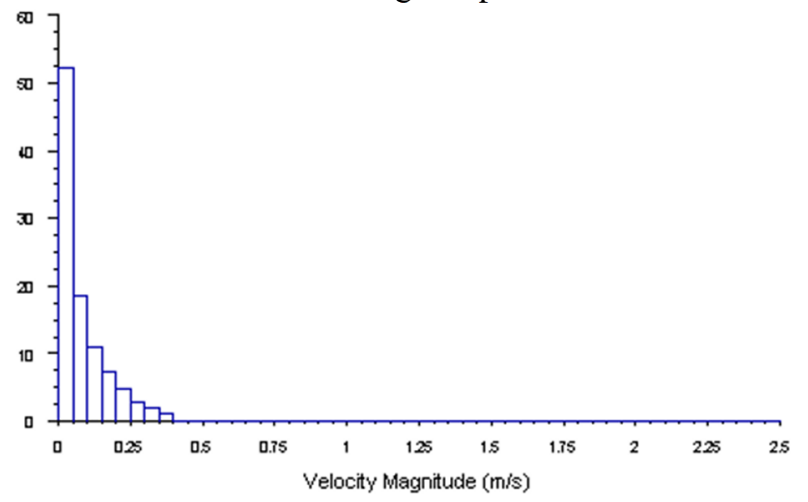

A

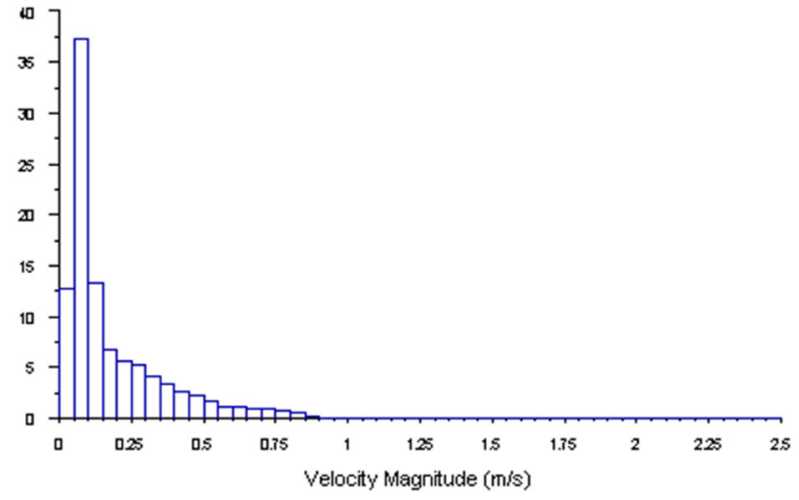

B

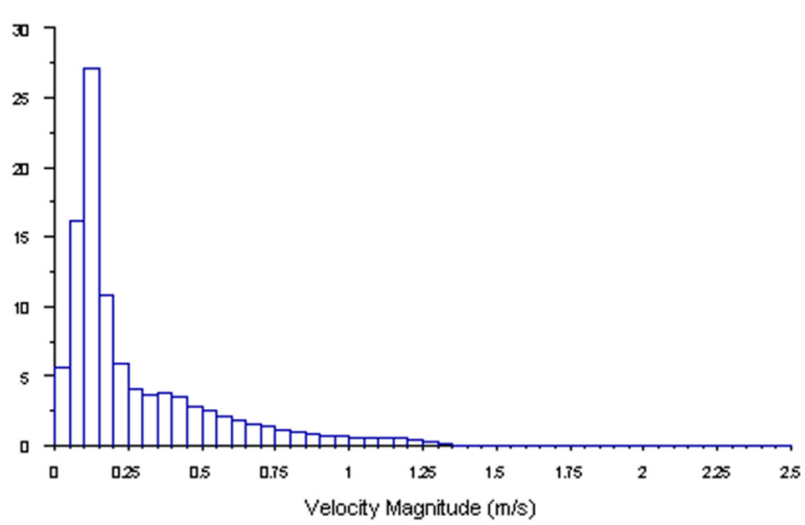

C

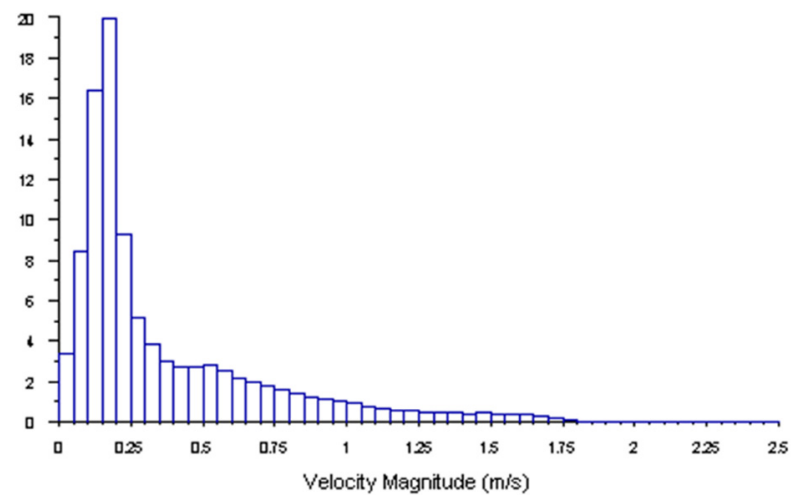

D

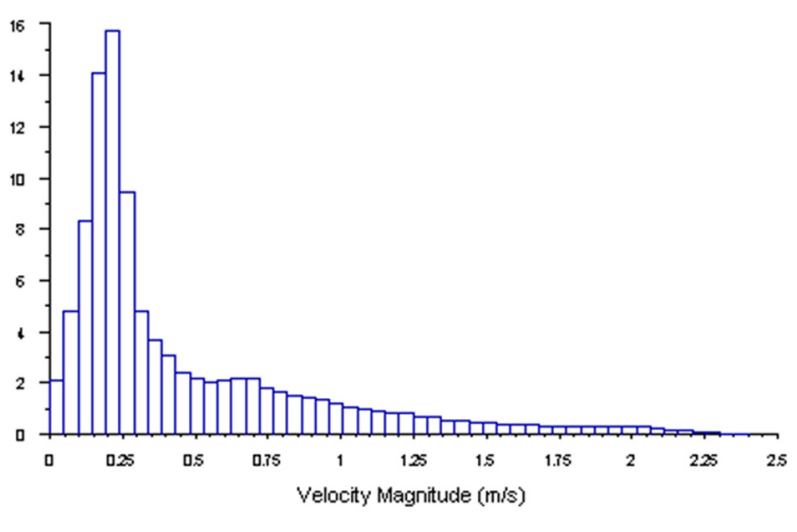

E

Fig. 9. Probability distribution map of single layer mixing velocity 
The average velocity is calculated by volume weighting method. The volume weighted averaging of a quantity is to multiply the field variables by the mesh volume, then sum the product and divide it by the total volume. The formula can be expressed as follows:

$$
\bar{v}=\frac{1}{V} \int v d V=\frac{1}{V} \sum_{i=1}^{n} v_{i}\left|V_{i}\right|
$$

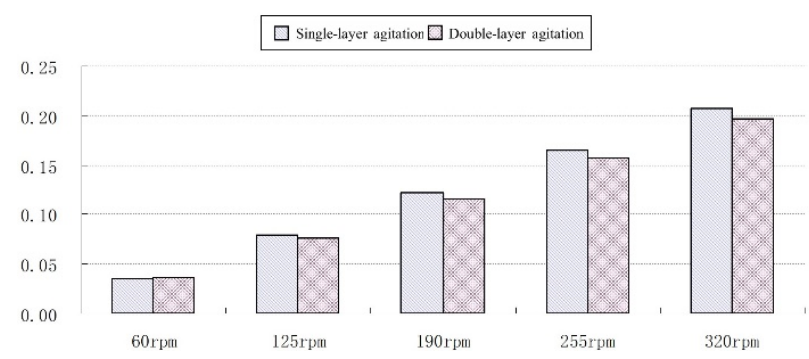

Fig. 10. Average velocity histogram

At $125-320 \mathrm{rpm}$, the average speed of double-layer mixing is less than that of single-layer mixing, but at 60 $\mathrm{rpm}$, the speed of double-layer mixing is higher than that of single-layer mixing. This may be due to the fact that double-layer stirring is more uniform at low speed without considering power input, while at high speed, the local velocity increase caused by single-layer stirring increases the average value, but the overall uniformity is not as good as double-layer stirring. This can be found in Figure10.

It is generally believed that the greater the fluctuation of velocity value, the more violent the disturbance is. Mean value and standard deviation are used to express the fluctuation. The standard deviation reflects the degree of dispersion of the value relative to the average value. The larger the standard deviation, the greater the fluctuation of velocity. Obviously, the variance of double-layer stirring is obviously smaller than that of single-layer stirring, and the uniformity of double-layer stirring is obviously better than that of single-layer stirring from Figure11.

The formula for calculating standard deviation is as follows:

$$
\sigma=\sqrt{\frac{\sum_{i=1}^{N}\left(X_{i}-\bar{X}\right)^{2}}{N}}
$$

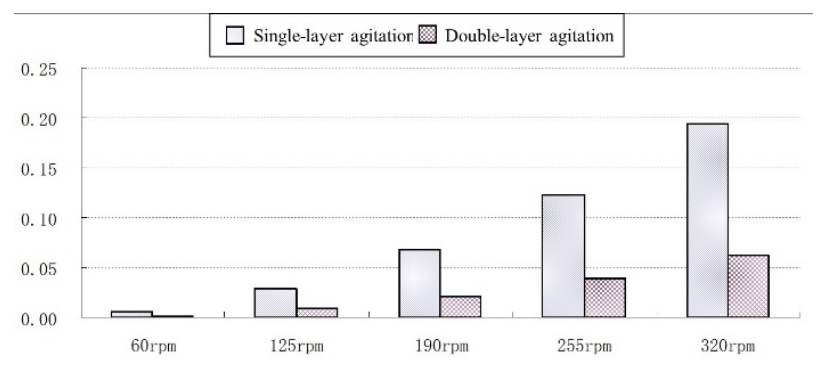

Fig. 11. Velocity variance map

\section{Conclusion}

In this paper, computational fluid dynamics (CFD) simulation of the flow field in a fully mixed stirred anaerobic reactor is carried out, which is divided into two groups: a single-layer six-blade open-ended turbine impeller with baffles and a double-layer four-blade inclined 45-degree impeller. The flow field inside the reactor is calculated and analyzed quantitatively. The effects of blade and stirring speed are investigated. The conclusions are as follows:

(1) Streamline distribution is made for single-layer six-blade open turbine propeller, and axial section and velocity data are analyzed. There are two fluid ring structures in the velocity vector of the axial section, which are located at the upper and lower parts of the impeller respectively. There is also a small planar fluid ring at the bottom of the reactor.

(2) The analysis of double-layer agitation shows that the double-layer oblique upward propeller can produce better axial velocity distribution, which is more conducive to the formation of large fluid loop structure of up and down circulation.

(3) At 125-320 rpm, the average speed of double-layer mixing is less than that of single-layer mixing, but at 60 $\mathrm{rpm}$, the speed of double-layer mixing is higher than that of single-layer mixing. This may be due to the fact that double-layer stirring is more uniform at low speed without considering power input, while at high speed, the local velocity increase caused by single-layer stirring increases the average value, but the overall uniformity is not as good as that of double-layer stirring.

\section{References}

1. J.M.Jing,NATURAL GAS INDUSTRY, 2008, 28(1):149-153.

2. $\mathrm{Wu}, \mathrm{B}$. and S. Chen, Biotechnology and Bioengineering, 2008. 99(3): 700-711.

3. H. Liua , G.M. Jiang, H.Y. Zhuang. Renewable and Sustainable Energy Reviews ,2008,12,1402-1418.

4. H.X.Shi, T.Lu, H.G.Zhu, et al. Journal of Agricultural Machinery, 2014, 45 (1): 143-149.

5. H.X.Shi,T.Wang, H.G.Zhu,.Journal of Agricultural Engineering. 2010, 02, 268-273.

6. AngéliqueDelafosse, Marie-LaureCollignon, Chemical Engineering Science, 2014,106,76-85.

7. Shen F, Tian L, Yuan H, et al. Applied Biochemistry and Biotechnology, 2013, 171(3):626642.

8. Bello-Mendoza R, Sharratt P N. WATER SCIENCE AND TECHNOLOGY. 1999, 40(8): 49-56.

9. $\mathrm{Yu} \mathrm{L}, \mathrm{Ma} \mathrm{J}, \mathrm{Chen} \mathrm{S}$. BIORESOURCE TECHNOLOGY. 2011, 102(2): 1012-1018.

10. Deng L, Li Y, Chen Z, et al. APPLIED ENERGY. 2014, 114(SI): 504-511.

11. Brucato A, Ciofalo M, Grisafi F, et al. Chemical engineering Science,

12. Wu, B., Water Research, 2010. 44(13): 3861-3874.

13. Parvareh, A., et al., International Communications in Heat and Mass Transfer, 2010. 37(3): 304-311. 
14. Karteris A, Papadopoulos A, Balafoutas G. Modeling. WATER AIR AND SOIL POLLUTION. 2005, 162(1-4): 107-125.

15. $\mathrm{Wu}$ B. COMPUTERS AND ELECTRONICS IN AGRICULTURE. 2013, 93: 195-208.

16. Vesvikar, M.S. and M. Al-Dahhan, Biotechnology and Bioengineering, 2005. 89(6): 719-732.

17. F.J.Wang. Computational Fluid Dynamics - Principle and Application of CFD Software. 2004.

18. Ranade, V.V., J.R. Bourne, and J.B. Joshi. Chemical Engineering Science, 1991. 46(8): 1883-1893.

19. Tamburini, A., et al. Chemical Engineering Research and Design, 2009. 87(4): 587-597.

20. H.Yang, L.W.Deng, et al. China Biogas, 2010.28(4): 3-9.

21. Ihejirika I, Ein-Mozaffari F. Chem Eng Technol 2007;30:606-14.

22. H.G.Zhu, J.W.Bi, H.X.Shi. Journal of Agricultural Machinery, 2011, 06, 127-131.

23. Karim, K., et al. Bioresource Technology, 2005. 96(16): 1771-1781.

24. Stenstrom, M.K., et al. Journal of Environmental Engineering, 1983. 109(5): 1148-1158. 